\title{
Revisiting IF/TA Category of Banff Working Classification of Renal Allograft Pathology: Have the Objectives been Achieved?
}

\author{
Muhammed Mubarak ${ }^{*}$ and Javed I Kazi ${ }^{2}$
}

${ }^{1}$ Professor of Pathology, Sindh Institute of Urology and Transplantation (SIUT), Karachi, Pakistan

${ }^{2}$ Consultant Histopathologist, Histopathology Department, Sindh Institute of Urology and Transplantation (SIUT), Karachi, Pakistan

\begin{abstract}
Interstitial fibrosis/tubular atrophy (IF/TA) is, like its predecessor of Chronic Allograft Nephropathy (CAN), a purely descriptive designation depicting the morphological appearances of Chronic Sclerosing lesions observed on renal allograft biopsies in a variety of clinical settings. The term was introduced by the Banff classification in its 2005 meeting as a replacement for the then popular and often misunderstood category 5 of the Banff classification, i.e., the CAN. The aim was to encourage the transplant pathologists to look for and identify the specific causes of late allograft dysfunction on renal allograft biopsies and not just simply dump all the chronic transplant lesions into the paper wastebasket category of CAN. This editorial explores the rationale behind this change and whether the objectives stipulated have been achieved in real practice. We are of the view that the time has arrived to revisit this change of category and its impact on clinical practice in a systematic manner perhaps by one of the Banff working groups.
\end{abstract}

Keywords: Banff classification; Chronic changes; IF/TA; Kidney transplant; Morphology

InterstitialFibrosis/Tubular Atrophy (IF/TA) is, like its predecessor of Chronic Allograft Nephropathy (CAN), a purely descriptive designation depicting the micro-scopical appearances of chronic fibrosing lesions observed on renal allograft biopsies typically in the setting of chronic allograft dysfunction [1,2]. However, subclinical forms of IF/TA are also commonly observed on the protocol biopsies in well-functioning renal allografts [3-5]. The term was introduced by the Banff classification in its 2005 meeting as a replacement for the then popular category 5 of the Banff classification, i.e., the CAN $[1,6]$. The aim was to encourage the transplant pathologists to look for and identify the specific causes of late allograft dysfunction on renal allograft biopsies and not just simply dump all the chronic transplant lesions into the paper wastebasket category of CAN, so as to guide optimal patient management. Although it was recognized from the early days of Banff classification that CAN is a multi factorial process, caused by both immune and non-immune factors, and this led to the creation of "a" and "b" subtypes of CAN in the classification [7]. But apparently, little attempt was made in real practice by the reporting pathologists in sub-classifying CAN and assigning the proper etiological designation to individual cases. Moreover, the widespread use of the term of CAN led to misconception in the minds of many that it is a specific disease entity $[1,2,6]$. This prompted the Banff group to modify the nomenclature of this category and this lesion dominated the agenda of Banff 2005 meeting. The term of CAN was eliminated and the specific causes of renal allograft dysfunction were moved to other relevant categories of the classification. The category 5 now included only those cases of IF/ TA, for which no specific cause could be found, even after exhaustive search $[2,6]$. But, whether this change in the terminologies has resulted in better graft outcomes is still a big question. In other words, has this change in the classification translated into clinical practice? The pragmatic answer is 'No'. There is as yet no study of note reported from anywhere in the world addressing the impact of this change in the classification scheme on the graft outcomes. Or perhaps the question is premature. But eight years have elapsed since this change was effected. So, it is time for undertaking such a study comparing the graft outcomes using the earlier CAN classification and the new IFTA modification of the Banff classification. In this regard, the Banff Working Group (BWG) on fibrosis scoring can take an initiative [8]. Besides addressing the issues of reproducibility of the fibrosis scoring, the group can undertake the role of etiological exploration of renal allograft biopsies showing chronic histological lesions. To be honest, this is not an easy task for the reporting pathologist in routine practice, given the sampling variation, interobserver discordance and the lack of clear-cut specificity for the majority of the histological lesions. There is, therefore, a strong need for corroborating the morphological study of renal allograft biopsies with the newer technological approaches such as molecular genetic, omics and donor specific antibody studies to better define the "specific disease phenotypes" of chronic allograft injury [911]. This, then, perhaps can translate into better and personalized management of kidney transplant recipients and better long-term graft outcomes. This integration is all the more important and relevant in the context of IF/TA than in the setting of acute graft dysfunction [12-15].

In summary, the future of the renal transplant pathology lies in the integration of newer technological studies with the morphological and clinical studies to guide individualized management decisions with ultimate better long-term graft outcomes.

\section{References}

1. Mubarak M, Kazi Jl (2013) Evolution of the Banff working classification of rena allograft pathology: Updates and future directions. J Transplant Technol Res 3: e126.

2. Mubarak M, Kazi Jl. Evolution of the approaches toward grading and classifying chronic changes in the renal allograft: Banff classification updates III. Port J Nephrol Hypert (In press).

3. Nankivell BJ, Borrows RJ, Fung CL, O'Connell PJ, Allen RD, et al. (2003) The natural history of chronic allograft nephropathy. NEngl J Med 349: 2326-2333.

4. Legendre C, Thervet E, Skhiri H, Mamzer-Bruneel MF, Cantarovich F, Noël $\mathrm{LH}$, et al. (1998) Histologic features of chronic allograft nephropathy revealed by protocol biopsies in kidney transplant recipients. Transplantation; 65: 15061509.

*Corresponding author: Dr. Muhammed Mubarak, Professor of Pathology, Histopathology Department, Sindh Institute of Urology and Transplantation, Karachi-74200, Pakistan, Tel: 009221 99215752; Fax: 009221 32726165; E-mail: drmubaraksiut@yahoo.com

Received July17, 2020 Accepted July 21, 2020; Published July 23, 2020

Citation: Mubarak M, Kazi Jl (2020) Revisiting IF/TA Category of Banff Working Classification of Renal Allograft Pathology: Have the Objectives been Achieved? J Transplant Technol Res 4: e129. doi:10.4172/2161-0991.1000e129

Copyright: (c) 2020 Mubarak M, et al. This is an open-access article distributed under the terms of the Creative Commons Attribution License, which permits unrestricted use, distribution, and reproduction in any medium, provided the original author and source are credited. 
Citation: Mubarak M, Kazi JI (2020) Revisiting IF/TA Category of Banff Working Classification of Renal Allograft Pathology: Have the Objectives been Achieved? J Transplant Technol Res 4: e129. doi:10.4172/2161-0991.1000e129

5. Nankivell BJ, Chapman JR (2006) Chronic allograft nephropathy: current concepts and future directions. Transplantation 81: 643-654.

6. Solez K, Colvin RB, Racusen LC, Sis B, Halloran PF, et al. (2007) Banff '05 Meeting Report: differential diagnosis of chronic allograft injury and elimination of chronic allograft nephropathy ('CAN'). Am J Transplant 7: 518-526.

7. Racusen LC, Solez K, Colvin RB, Bonsib SM, Castro MC, et al. (1999) The Banff 97 working classification of renal allograft pathology. Kidney Int 55: 713723.

8. Sis B, Mengel M, Haas M, Colvin RB, Halloran PF, et al. (2010) Banff '09 meeting report: antibody mediated graft deterioration and implementation of Banff working groups. Am J Transplant 10: 464-471.

9. Brouard S, Renaudin K, Soulillou JP (2011) Revisiting the Natural History of IF/ TA in Renal Transplantation. Am J Transplant 11:647-649.

10. Mengel M, Chang J, Kayser D, Gwinner W, Schwarz A, Einecke G, et al.
(2011) The molecular phenotype of 6-week protocol biopsies from human renal allograft: Reflections of prior injury but not future course. Am J Transplant 11: 708-718.

11. Perkins D, Verma M, Park KJ (2011) Advances of genomic science and systems biology in renal transplantation: a review. Semin Immunopathol 33:211-218.

12. Mengel M, Sis B, Haas M, Colvin RB, Halloran PF, et al. (2012) Banff 2011 Meeting report: new concepts in antibody-mediated rejection. Am J Transplant 12: 563-570.

13. Weening JJ (2008) The art of classifying renal allograft pathology. Nat Clin Pract Nephrol 4: 420-421.

14. Solez K (2010) History of the Banff classification of allograft pathology as it approaches its 20th year. Curr Opin Organ Transplant 15: 49-51.

15. Solez K, Racusen LC (2013) The Banff classification revisited. Kidney Int 83: 201-206. 